\title{
Epicardial adipose hypertrophy: The Phantom of the Opera
}

\author{
José M. Bernal, MD, PhD, ${ }^{a}$ and Carlos A. Mestres, MD, PhD, FETCS ${ }^{b}$

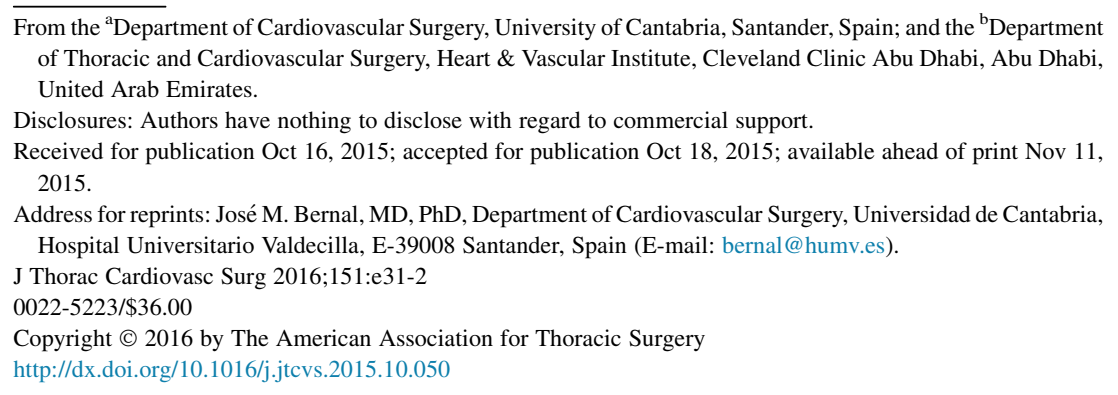

In the 21 st century, what we cannot find in databases of scientific literature is unlikely to exist. It would seem that nothing can be absent from databases that currently contain all the research published until today. A quick look at PubMed, a service of the US National Library of Medicine, confirms that as of today it comprises 25 million citations for biomedical literature from MEDLINE, the National Library of Medicine database, life science journals, and online books. It is therefore surprising to read the description in the article published by Smail and colleagues ${ }^{1}$ in this issue of the Journal. This article is devoted to the description of a case of surgical resection of circumferential epicardial adipose tissue hypertrophy in a 54-year-old female patient who was seen for the clinical suspicion of acute coronary syndrome and in whom magnetic resonance imaging confirmed tamponade caused by epicardial adipose tissue. The patient was, as described in the article, radically treated with surgical excision of the thick epicardial fat pad. The case was quite uncommon, though, exceptional perhaps.

Cardiac lipomatous hypertrophy has exceptionally been reported. It involves mostly the interatrial septum. It is likely that the first description was that of Prior $^{2}$ in 1964 from a postmortem examination. With the newer imaging techniques, especially multidetector computed tomography or magnetic resonance imaging, the number of detected cases has increased. There is some confusion regarding the terminology for fatty tissue of the heart. Intrapericardial lipomas originate in the epicardium and may lead to compressive or arrhythmogenic effect, but they have given identifiable forms. ${ }^{3}$ What Smail and colleagues ${ }^{1}$ describe, however, is a new clinicopathologic entity, not previously published as such, that cannot be located across databases and therefore did not officially exist until now. The novelty described by Smail and colleagues ${ }^{1}$ is their finding of epicardial cardiac lipomatous hypertrophy that behaved like constrictive pericarditis.

Nihil novum sub sole. Nothing new under the sun. And as Smail and colleagues ${ }^{1}$ wisely note, in 2004 Myerson and

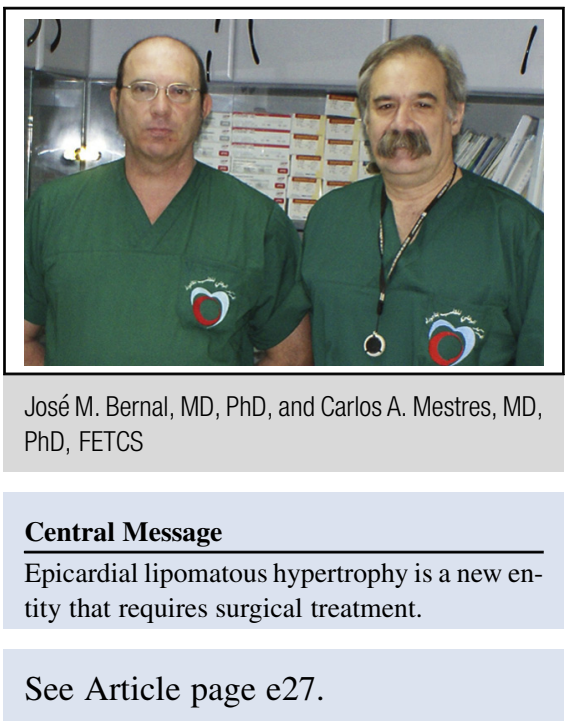

associates $^{4}$ described a similar case of a 72 -year-old patient with tamponadelike effect, a fat tamponade caused by cardiac lipomatous hypertrophy and surgically treated with pericardiectomy, which was useful to improve symptoms. The novelty described by Smail and colleagues ${ }^{1}$ is that their surgery did not treat symptoms but aimed at excising the cause, the excess lipomatous tissue. The relevant aspect is that there was lipomatous hypertrophy of the interatrial septum, a fact that could make the clinical and pathologic diagnosis easy.

The question now is whether we have to turn our attention to the epicardial fat regardless of form and thickness. It may happen that there is hidden information, and no attention has been paid to this strange and neglected tissue in the past. It is known to be associated with such cardiovascular dysautonomic symptoms as orthostatic hypotension and conduction abnormalities, and it has been a focus of attention in Parkinson disease. ${ }^{5}$ In a previous study, we were able to detect abnormal and phospho- $\alpha$-synuclein aggregates in the epicardial fat of $7.7 \%$ of 91 unselected individuals in epicardial fatty areas more likely to contain autonomic nervous tissue. ${ }^{6}$ Intraneuronal aggregates of the presynaptic protein $\alpha$-synuclein in Lewy bodies and neurites constitutes the pathologic hallmark of Parkinson disease. Although in different directions from what Smail and colleagues ${ }^{1}$ have described, there may be some room for future research on a tissue that has been treated as a phantom but that we know really exists. 
Smail and colleagues ${ }^{1}$ must be commended for an exhaustive work and the significantly valuable imaging produced. This brief contribution and the associated analysis of the scanty knowledge available may trigger a renewed interest in epicardial fat as research material.

\section{References}

1. Smail H, Baciu A, Dacher JN, Litzler PY. Surgical resection of circumferential epicardial adipose tissue hypertrophy: case report and systematic review of the literature. J Thorac Cardiovasc Surg. 2016;151:e27-30.
2. Prior JT. Lipomatous hypertrophy of cardiac interatrial septum. A lesion resembling hibernoma lipoblastomatosis and infiltrating lipoma. Arch Pathol. 1964;78:11-5.

3. Schrepfer S, Deuse T, Detter C, Treede H, Koops A, Boehm DH, et al. Successful resection of a symptomatic right ventricular lipoma. Ann Thorac Surg. 2003;76: $1305-7$.

4. Myerson SG, Roberts R, Moat N, Pennell DJ. Tamponade caused by cardiac lipomatous hypertrophy. J Cardiovasc Magn Reson. 2004;6:565-8.

5. Oka H, Toyoda C, Yogo M, Mochio S. Cardiovascular dysautonomia in de novo Parkinson's disease without orthostatic hypotension. Eur J Neurol. 2011;18: 286-92.

6. Navarro-Otano J, Gelpi E, Mestres CA, Quintana E, Rauek S, Ribalta T, et al. Alpha-synuclein aggregates in epicardial fat tissue in living subjects without parkinsonism. Parkinsonism Relat Disord. 2013;19:27-31; discussion 27. 